University of Wollongong

Research Online

Faculty of Business - Papers (Archive)

Faculty of Business and Law

$1-1-2015$

Economic growth and environment: tourism as a trigger for green growth

Simone Marsiglio

University of Wollongong, simonem@uow.edu.au

Follow this and additional works at: https://ro.uow.edu.au/buspapers

Part of the Business Commons

Research Online is the open access institutional repository for the University of Wollongong. For further information contact the UOW Library: research-pubs@uow.edu.au 


\title{
Economic growth and environment: tourism as a trigger for green growth
}

\begin{abstract}
The author analyses the implications of tourism activities on economic growth and environmental assets, focusing especially on small island countries. She develops a stylized dynamic economic model in which tourism is the trigger of the incentive mechanism leading to abatement activities and economic growth. The basic idea is that tourists choose the location to visit according to a number of factors (including environmental quality) which are affected by residents' choices. If residents engage in environmental protection activities, it then may be possible for environmentally-based tourism economies to reach a smooth development process. The author shows that the (sustainable) balanced growth path is the only viable equilibrium, and along such a path consumption grows while environmental quality rises. Tourists' preferences crucially affect the long-run outcome, since economic and environmental growth rates increase with the green preference and decrease with the grey preference and crowding aversion parameters. Thus, if tourism specialization is to be the pathway to development, green tourism will need to be promoted.
\end{abstract}

\section{Keywords}

economic, environment, growth, green, trigger, tourism

Disciplines

Business

\section{Publication Details}

Marsiglio, S. (2015). Economic growth and environment: tourism as a trigger for green growth. Tourism Economics: the business and finance of tourism and recreation, 21 (1), 183-204. 


\title{
Economic growth and environment: tourism as a trigger for green growth
}

\author{
SimONE MARSIGLIO \\ School of Accounting, Economics and Finance, University of Wollongong, Northfields Avenue, \\ Wollongong 2522 NSW, Australia.E-mail: simonem@uow.edu.au
}

\begin{abstract}
The paper analyses the implications of tourism activities for economic growth and environmental assets, focusing especially on small island countries. The author develops a stylized dynamic economic model in which tourism is the trigger of the incentive mechanism leading to abatement activities and economic growth. The basic idea is that tourists choose the location to visit according to a number of factors (including environmental quality) which are affected by residents' choices. If residents engage in environmental protection activities, it then may be possible for environmentally based tourism economies to reach a smooth development process. The author shows that the (sustainable) balanced growth path is the only viable equilibrium, and along such a path consumption grows while environmental quality rises. Tourists' preferences crucially affect the longrun outcome, since economic and environmental growth rates increase with the green preference and decrease with the grey preference and crowding aversion parameters. Thus, if tourism specialization is to be the pathway to development, green tourism will need to be promoted.
\end{abstract}

Keywords: economic growth; environment; tourism and growth; sustainability; small island countries

JEL Classification: $\mathrm{O} 40, \mathrm{O} 41, \mathrm{Q} 50, \mathrm{Q} 56$

In the last decades, there has been a slowly growing consensus that human activity is dramatically affecting our planet's climate, biological mix and natural resources. As a recognition of this, much research analyses the implications of social, demographic and economic activities on the environmental and climatic changes the planet has been facing. In the economics literature, much attention

I wish to thank, without implicating, Pasquale Sgro and Natalie Stoeckl for insightful discussions and advice. I also thank participants in seminars held at JCU and the University of Eastern Piedmont, and participants in the Fourth Conference of the International Association for Tourism Economics (University of Ljubljana, Slovenia) for helpful suggestions. Two anonymous referees provided constructive comments on an earlier draft of the paper. All remaining errors and omissions are my own sole responsibility. 
is paid to the effects of economic development on natural assets, and in particular on the possibility that economic growth and environmental preservation are eventually incompatible (Solow, 1974; Stokey, 1998). Recently, a new interest is growing about the implications of tourism activity for both the economic and environmental performance, since

'Having grown faster than world GDP since the 1950s, international tourism is today one of the most important tradable sectors, with expenditure on tourist goods and services representing some $8 \%$ of total world export receipts and 5\% of world GDP'. (Lanza et al, 2003, p 315).

Tourism, as any other human activity, is based on a deep and complex bilateral relationship with the surrounding environment, which affects and is affected by tourists' inflows (Budowsky, 1976). On the one hand, environmental assets are a fundamental determinant of tourists' destination choice and, on the other hand, tourism has negative effects on the environment (Davies and Cahill, 2000). Many poor and developing countries still have abundant natural resources, which give them a natural advantage in the production of tourism services. It is thus important to understand how to manage tourism activities optimally to promote a smooth process of economic development.

Within this framework, the notion of sustainability has become particularly popular lately. Since the Brundtland report, which first introduced the definition of sustainable development, one of the top priorities for policymakers and researchers has been to look for, among other things, a specific pathway that satisfies 'the needs of the present without compromising the ability of future generations to meet their own needs' (WCED, 1987, p 16). Similarly, the necessity of addressing the development of different economies along a sustainable tourism path has been pointed out by several studies (Pigram, 1990; Dearden, 1991). An appropriate definition of sustainable tourism is 'tourism which meets the needs of present tourists and host regions while protecting and enhancing opportunity for the future' (WTO, 1998, p 21). Thus, by linking with the Budowsky (1976) symbiosis scenario, ${ }^{1}$ it refers to a certain type of tourism that wisely uses and preserves natural resources to maintain their longterm viability and thus their capacity to produce welfare services to tourists, and the whole population in general. Essentially, sustainable tourism involves the minimization of tourism's negative impacts on the environment (and eventually the maximization of its positive impacts on economic development). There are, however, serious concerns in the tourism literature about the real possibility of reaching and implementing a sustainable tourism pathway (Casagrandi and Rinaldi, 2002). In this paper, we attempt to contribute to this debate by adopting a macroeconomic point of view, and in particular an economic growth standpoint, focusing on the economic incentives for tourism firms to engage in environmental protection activities.

The main question we wish to answer here is whether it is possible for an economy specialized in tourism to achieve long-run growth, ensuring that its natural resources are used sustainably. From an economic point of view, the issue is particularly relevant if we consider that many developing countries endowed with natural resources, such as pristine beaches, beautiful mountains, undisturbed wildlife and a rich biodiversity mix, are now facing the choice between 
mass tourism and green tourism. Some examples are the Caribbean, Indian Ocean and south Pacific islands, which every year are chosen as holiday destinations by an increasing number of tourists worldwide; the choice of these countries is going to have, mainly through the channel of climate change, not only a local impact on their ecosystems and natural assets but also on vast surrounding areas (the entire Caribbean Gulf, the whole Indian and Pacific Oceans) leading to potentially tremendous impacts on the welfare of a large share of people worldwide. A satisfactory answer to our question cannot be found in the existing literature, since existing works separately address either the relationship between tourism and growth (Hazari and Sgro, 1995; Lanza and Pigliaru, 2000; Lanza et al, 2003; Brau et al, 2007) or the linkage between tourism and the environment (Candela and Cellini, 2006; Cerina, 2007; Giannoni and Maupertuis, 2007; Lozano et al, 2008).

The literature on tourism and growth is mostly empirical and concludes that tourism specialization is to a large extent successful. From the theoretical side, most papers focus on dynamic models of trade, and the general conclusion is that, as long as tourism demand increases by a higher rate than world income, a terms of trade effect determines whether tourism and growth move in the same direction (Hazari and Sgro, 1995). Since tourism demand shows a low elasticity of substitution (Lanza et al, 2003; Brau et al, 2007), tourism is beneficial for growth if the international terms of trade move in favour of tourism services (Schubert et al, 2011). On the empirical side, several works analyse the implications of tourism for the growth performance of different economies during the last decades of the 20th century. Lanza et al (2003) show that even in developed countries the effect can be positive, even though productivity growth in tourism is lower than in other sectors. Brau et al (2007), by considering the period 1980-2003, show that tourism countries grow significantly faster than others, including OECD, oil exporters, developing economies and small countries. Also Lanza and Pigliaru (2000) confirm this result by underlining that in 1985-1995, 7 of the 15 fastest growing countries were tourism countries, and that what matters for the ability of a country to successfully specialize in tourism is its relative endowment of natural resources, rather than its absolute size; in fact, a relevant and large share of rapidly growing tourism countries are small countries, and to a large extent small islands (Antigua and Barbuda, Cyprus, Maldives, Mauritius, Seychelles, Singapore, and St Kitts and Nevis).

The tourism and environment literature, instead, mainly develops alternative theoretical frameworks to study the long-run effects of tourism on the natural assets of tourism destinations. From the empirical point of view, Tisdell (2001) points out that environmental resources, on the one hand, positively affect tourists' preferences towards a particular location and, on the other hand, are negatively affected by tourist inflows. Davies and Cahill (2000) show that tourism has large impacts on the environment, comprising energy and water consumption, production of waste, effects on water and air quality, alteration and fragmentation of ecosystems and impacts on wildlife and on aesthetic and cultural environment. From the theory perspective, Candela and Cellini (2006) adopt a microeconomic approach by analysing a differential game where tourism destinations compete in an oligopolistic market by choosing how much to invest in environmental preservation and differentiation efforts. Giannoni and 
Maupertuis (2007) employ a dynamic model focusing on the trade-off between investments in tourism infrastructure and their impact on environmental quality. The paper closest to ours is that by Cerina (2007), which develops a tractable framework (which we shall borrow to a large extent) for analysing the connections between residents' choices (about consumption and environmental preservation efforts) and tourism demand and flows, and their joint effects on the environment. The model however abstracts completely from capital accumulation and economic growth results to be completely exogenous; moreover, the pollution abatement effort is also exogenous and thus environmental dynamics turns out to be trivial. This paper seeks to address these shortcomings by elaborating a more detailed macroeconomic sector useful to present some policy insights. In particular, it allows for the economic and environmental growth rates of the tourism economy to be endogenous as resulting from agents' choices about consumption levels and environmental preservation efforts. Lozano et al (2008) take a first step in this direction, by introducing capital accumulation along with the provision of public goods and services by the government, but their model turns out to be so complex that no analytical solution can be found and thus no policy implications can be inferred.

In tourism studies, much attention is placed on the concept of tourism area life cycle introduced by Butler (1980), which claims that

'a tourism destination experiences several stages of development that eventually end in stagnation. These stages are differentiated by several factors, such as the number of visitors, tourists' motivations, the residents' perception of the tourism phenomenon, or the degree of environmental damage'. (Lozano et al, 2008, p 728)

According to such a hypothesis, for tourism activity to be sustainable we need alternate phases of high and low visitor numbers, permitting ecosystems to regenerate. Note that in developing economies dependent on tourism, since income to a large extent depends on tourism profits, this may imply dramatic welfare consequences. It is therefore crucial for the well-being of local communities to find a sustainable tourism pathway that allows for a smooth development process. In this paper, we argue that such an outcome is possible, as long as tourism firms allocate some resources to reduce the adverse impact of tourism on the environment; this might happen because long-term profits from tourism represent an important stimulus for engaging in environmental protection activities that support the ecosystem's own regeneration capacity and lead to green growth.

The paper proceeds as follows. The next section develops the baseline dynamic general equilibrium model with the main focus on economies specialized in tourism, where crowding-averse tourists are attracted by the quality of environmental assets and by the stock of tourism facilities available in the economy. ${ }^{2}$ The resident household-firm agent has to determine how to manage the trade-off between developing tourism facilities and preserving environmental quality, by deciding how much to invest in tourism services and in environmental protection activities. In the third section we analyse the steady state outcome, and show that the economy lies at any instant of time on its sustainable balanced growth path equilibrium, along which consumption, in- 
come and environmental quality grow at constant rates. Tourists' preferences determine its economic and environmental growth rate, and in particular greener (greyer) preferences lead to better (worse) economic and environmental performances. The fourth section presents an interpretation of the model, which best suits in describing the challenges faced by small island countries, such as those populating the Caribbean, the Indian and the South Pacific Ocean. Small economies are characterized by the 'luxury of limited choice' (Persaud, 2011), which means they do not have any choice but exploiting their comparative advantages, which are the drivers of tourist inflows. The fifth section considers two straightforward extensions of the model to allow for tourists' demand to be also affected by the provision of public goods by the government or other local authorities, and for a richer tourist flows function depending not only on environmental quality but also on human-built facilities. We show that even in these two contexts, the qualitative results will not be substantially different from our baseline model, meaning that it is a good benchmark for the analysis of tourism activities on both the economic and environmental sides of small tourism-based economies. In the last section we present concluding remarks and propose directions for future research. The Appendix contains the equilibrium and transitional dynamics analysis of the detrended system of differential equations, for both the baseline and extended models.

\section{The baseline model}

The model is a Ramsey-type (1928) optimal growth model, in which the (resident) household-firm agent seeks to maximize its welfare given the resource constraints and initial conditions. In order to keep the model tractable and simple, we adopt the framework developed in Cerina (2007) to describe the international tourism market and tourists' preferences. As in Xepapadeas (2005), we consider environmental quality as a stock variable, while pollution flows can be abated through purposive and costly activities; emissions abatement costs are assumed to be convex as in Bartz and Kelly (2008). Finally, for the sake of simplicity, tourism inflows are proportional to environmental quality.

\section{International tourism market and tourist preferences}

As in Cerina (2007), we consider a small economy producing only tourism services (accommodation, restaurants, leisure facilities and so forth), supplied in an international tourism market populated by a large number of tourism economies. The produced tourism services need to be interpreted as a bundle of goods and services able to satisfy a wide range of tourism needs. Concerning the nature of the international tourism market, we should consider that:

'although international competition fixes the price for a given quality of the services, a country could charge a higher price provided its services are considered of a higher quality (that is, characterized by a higher stock of environmental, cultural and social resources) than other countries. In other words, the international market consists of a continuum of tourism markets differentiated by their quality and the (equilibrium) price paid for the tourism services. In each of them, the suppliers are price-takers, but they 
can move along the quality ladder due to changes in their environmental quality'. (Cerina, 2007, pp 556-557)

The tourist flow comes from the international market and thus there is no distinction between resident and non-resident tourists.

The international demand for tourism is infinite at the price level corresponding to tourists' willingness to pay and nil for any other price level. As a consequence, at equilibrium the quantity of tourism is totally determined by the supply-side, ${ }^{3}$ which is composed of a large number of household-firm producing tourism services. With respect to Cerina (2007), who assumes that tourists' preferences depend on the quality of the environment, $e_{t}$, and the number of tourists itself, $z_{t}$, we assume ${ }^{4}$ that they depend also on the stock of tourism facilities, $k_{t}$. By relying on Rosen's (1974) hedonic pricing theory (Cerina, 2007), the willingness to pay for tourism services is given by:

$$
p_{t}=p\left(k_{t}, e_{t}, z_{t}\right)=a k_{t}^{\alpha} e_{t}^{\phi} z_{t}^{-\mu},
$$

where $a>0$ is a scale parameter, $0<\alpha, \phi<1$ measure the degree of tourists' sympathy towards tourism facilities and environment, respectively, while $\mu \in \mathbb{R}$ determines their degree of crowding aversion. It is reasonable to assume that the better the quality of tourism facilities and environment, the better the tourism experience, and therefore the higher the willingness to pay for the service. Since $\phi$ and $\alpha$ quantify the magnitude of tourists' passion for natural and human-built goods, we shall interpret them as the 'green' and 'grey' preference parameters, respectively. The assumption $0<\alpha, \phi<1$ states that, reasonably, the willingness to pay for tourism services is increasing and concave in $k_{t}$ and $e_{t}$. It is not so obvious what the relationship between the willingness to pay and tourism intensity should be. Tourists could be crowding averse $(\mu>0)$, crowding indifferent $(\mu=0)$ or crowding lover $(\mu<0)$. In order to allow for different types of preferences with respect to crowd, we do not attach a priori any restriction on the sign of $\mu$ itself. $^{5}$ Each tourist buys one unit of tourism services such that output is measured in terms of tourist entries. Tourism revenues are then:

$$
y_{t}=p\left(k_{t}, e_{t}, z_{t}\right) z_{t}=a k_{t}^{\alpha} e_{t}^{\phi} z_{t}^{1-\mu} .
$$

\section{Environmental quality and residents behaviour}

As in Xepapadeas (2005), environmental quality is a stock variable, the dynamics of which depend on the difference between its regeneration (or pollution absorption) capacity, $r\left(e_{t}\right)$, and unabated pollution, $b_{t}: \dot{e}_{t}=r\left(e_{t}\right)-b_{t}$. As in Marsiglio (2011), we assume that the environmental regeneration capacity is unbounded, $r^{\prime}\left(e_{t}\right)>0$, and for the sake of simplicity it is a linear function of the environmental quality, $r\left(e_{t}\right)=r e_{t}$, where $r>0$ measures its natural rate of regeneration. As in Cerina (2007) and Lozano et al (2008), pollution, $x_{t}$, is assumed to be a by-product of tourism activities (consistently with Budowsky's (1976) conflict scenario), $x_{t}=d z_{t}$, where $d>0$ measures the degree of pollution intensity. However, the tourism economy (the household-firm) may undertake costly abatement activities, which reduce the amount of pollution to $u_{t} x_{t}$, where 
$0<u_{t}<1$ denotes the fraction of emission abated, such that unabated emissions result to be $b_{t}=\left(1-u_{t}\right) x_{t}$. Given these assumptions, the law of motion of the environment reads as:

$$
\dot{e}_{t}=r e_{t}-d\left(1-u_{t}\right) z_{t} .
$$

Residents are characterized as traditional macroeconomic household-firm agents, who own the firms and rent their (tourism) capital to such firms in order to produce tourism services. The size of the household is normalized to 1 for the sake of simplicity. Its lifetime welfare is given by the infinite discounted $(\rho>0$ is the pure rate of time preference) sum of the instantaneous utilities, assumed to be isoelastic in the only argument, the consumption level, $c_{t}$ :

$$
u\left(c_{t}\right)=\frac{c_{t}^{1-\sigma}-1}{1-\sigma},
$$

where $\sigma>1$ is the inverse of the intertemporal elasticity of substitution (assumed to be greater than unity, as standard in growth theory). Its problem consists of choosing how much to consume given the income it receives by producing tourism services, $y_{t}$, and how much to invest in tourism services, $\dot{k}_{t}$. Since its revenues depend on environmental quality, which positively affects tourist preferences (and willingness to pay) and allows its firm to move along the quality ladder of the international tourism market, it has also to determine how much to invest in environmental protection activities. The cost of emissions abatement is $c\left(u_{t}\right) y_{t}$. The household-firm problem reads as follows:

$$
\begin{array}{rl}
\max _{c_{t}, u_{t}} & W=\int_{0}^{\infty} \frac{c_{t}^{1-\sigma}-1}{1-\sigma} e^{-\rho t} d t \\
\text { s.t. } \quad \dot{k}_{t} & =\left[1-c\left(u_{t}\right)\right] y_{t}-c_{t} \\
\dot{e}_{t} & =r e_{t}-d\left(1-u_{t}\right) z_{t},
\end{array}
$$

together with given initial conditions, $k_{0}$ and $e_{0}$. It is reasonable to assume that the cost function is increasing and convex, $c^{\prime}\left(u_{t}\right)>0$ and $c^{\prime \prime}\left(u_{t}\right)>0$, meaning that it gets more and more costly to abate larger shares of emissions (Candela and Cellini, 2006; Bartz and Kelly, 2008). As in Bartz and Kelly (2008), the cost function is assumed to take the following suitable form:

$$
c\left(u_{t}\right)=1-\left(1-u_{t}\right)^{\epsilon},
$$

with $\epsilon>1$. Such a specification results to be very convenient since it permits to simplify dramatically the following analysis, allowing for an explicit analytical solution.

\section{Tourism and general equilibrium}

Since our main concern is related to the effects of tourism on the environment of the accommodating destination, we need to specify the relationship between the tourist flows and the domestic economy. For the sake of simplicity, ${ }^{6}$ we assume that the tourist flow is proportional to environmental quality:

$$
z_{t}=v e_{t},
$$


where $v>0$ is a parameter determining the intensity of such a relationship. According to Equation (6), tourist flows are limited to a certain proportion of the stock of environmental assets, as the availability of beaches or other natural amenities (that is, a certain amount of square meters per tourist). If environmental quality increases over time tourism increases while if environmental quality decreases tourism falls. Under such an assumption, the dynamic problem of the household-firm agent can be recast as: ${ }^{7}$

$$
\begin{aligned}
\max _{c_{t}, u_{t}} W & =\int_{0}^{\infty} \frac{c_{t}^{1-\sigma}-1}{1-\sigma} e^{-\rho t} d t, \\
\text { s.t. } \quad \dot{k}_{t} & =\left(1-u_{t}\right)^{\epsilon} A k_{t}^{\alpha} e_{t}^{\theta}-c, \\
\dot{e}_{t} & =r e_{t}-\eta\left(1-u_{t}\right) e_{t},
\end{aligned}
$$

where $A=a v^{1-\mu}, \theta=1+\phi-\mu$ and $\eta=d v$. In this framework, it is reasonable to assume that $r<\eta$, meaning that in the case of no abatement activity $\left(u_{t}=0\right)$, environmental quality gets worse and worse. In such a scenario, the environmental growth rate would be negative, and in the long-run it will lead environmental quality to become so poor to be no longer appealing for tourists, who will then divert their demand to other destinations, completely cancelling the profits of the tourism sector. However, if the abatement activity is excessive $\left(u_{t}=1\right)$, environmental quality will grow according to its regeneration capacity, but this will require allocating all the income from tourism to such activities and no resources will be left for consumption. These two extreme situations are clearly not optimal for our household-firm agent, and thus we expect that the optimal solution will show a strictly positive and strictly lower than unity share of abated emissions.

Sufficiency of the above problem needs that $\alpha+\theta<1$, requiring the crowding aversion parameter to be sufficiently large, that is $\alpha+\phi<\mu$. This rules out the crowding indifferent $(\mu=0)$ and crowding lover $(\mu<0)$ cases. From now onward, we shall assume that this condition holds, along with that ensuring $\theta>0$, that is we shall assume that the crowding aversion parameter is positive and lies in a certain range, $\alpha+\phi<\mu<1+\phi$. Household-firm maximization yields to the following dynamic equations for consumption and share of abated pollution:

$$
\begin{aligned}
& \frac{\dot{c}_{t}}{c_{t}}=\frac{1}{\sigma}\left[\alpha\left(1-u_{t}\right)^{\epsilon} A k_{t}^{\alpha-1} e_{t}^{\theta}-\rho\right], \\
& -\frac{\dot{u}_{t}}{1-u_{t}}=\frac{1}{\epsilon-1}\left[\frac{\theta(\epsilon-1) \eta}{\epsilon}\left(1-u_{t}\right)-\theta r+\alpha \frac{c_{t}}{k_{t}}\right] .
\end{aligned}
$$

Equation (10) is the standard Keynes-Ramsey rule for consumption and states that consumption growth increases with the income to tourism capital ratio $\left(\frac{y_{t}}{k_{t}}\right)$ and decreases with the rate of time preference. Equation (11) says instead that the growth rate of the share of unabated emissions increases with the share 
of unabated emissions and the consumption to tourism capital ratio $\left(\frac{c_{t}}{k_{t}}\right)$, while it decreases with the rate of environmental regeneration.

\section{BGP analysis}

We now focus on the steady state outcome of our model economy, which is characterized by a balanced growth path (BGP) equilibrium, that is a path along which all the variables grow at constant rates. At equilibrium, it is clear from Equations (8) and (10) that the growth rate of tourism capital and consumption must be equal in order to have long-run growth, $\gamma \equiv \gamma_{c}=\gamma_{k}=\frac{\gamma_{y}}{\alpha+\theta}$. Moreover, from Equation (11), the share of abated emissions needs to be constant. It is therefore possible to show that along the BGP the growth rates of the economy, $\gamma$, and the environment, $\gamma_{e}$, are constant and positive.

Proposition 1: Assume $\frac{\epsilon \rho}{\theta}<\mathrm{r}<\frac{\theta \eta[1-\alpha+\epsilon(\sigma-1)]-\epsilon(1-\alpha) \rho}{\theta \epsilon(\sigma-1)}$. Then, the following results hold:

(i) Along the BGP, the share of unabated emission is constant and equal to:

$$
1-\overline{\mathrm{u}}=\frac{\epsilon[(\sigma-1) \theta \mathrm{r}+(1-\alpha) \rho]}{\theta \eta[1-\alpha+\epsilon(\sigma-1)]} \in(0,1),
$$

while the economic and environmental growth rates are strictly positive and respectively given by:

$$
\begin{aligned}
& \gamma=\frac{\theta \mathrm{r}-\epsilon \rho}{1-\alpha+\epsilon(\sigma-1)}, \\
& \gamma_{\mathrm{e}}=\frac{1-\alpha}{\theta} \gamma .
\end{aligned}
$$

(ii) The BGP is the only (non-trivial) viable equilibrium.

Proof: See the Appendix.

The technical condition $\frac{\epsilon \rho}{\theta}<r<\frac{\theta \eta[1-\alpha+\epsilon(\sigma-1)]-\epsilon(1-\alpha) \rho}{\theta \epsilon(\sigma-1)}$ in Proposition 1 is required in order to ensure that the growth rates are positive and that $0<1-$ $\bar{u}<1$. The BGP results to be locally unstable, and therefore the only possibility for our model economy to show balanced growth (to reach its non-trivial steady state) is to lie on such a path at any point in time. We can see that the growth rate of environmental quality is proportional to the economic growth rate, and they both depend positively on the rate of environmental regeneration and negatively on the rate of time preference. The intuition behind this result is clear: an increase in the rate of regeneration improves environmental quality (independently on agents effort in abatement activities) and therefore increases tourism, which determines resident agents' income; an increase in the rate of time preference increases the opportunity cost of investments and therefore lowers the incentives to abatement activities. 
It is noteworthy that the BGP equilibrium is sustainable since it is associated with increasing consumption (and therefore welfare) and cleaner environment (Brock and Taylor, 2010). This allows all the current and future generations to enjoy the benefits of economic development: larger consumption levels are experienced along with better environmental quality (WECD, 1987). Tourism itself emerges as sustainable too, since (present and future) tourists' demand is satisfied and host region needs are met. In fact, tourist flows are increasing over time since environmental quality improves, and this allows the tourism economy to proceed its development along a green direction; see Equation (6). This result highlights that sustainable tourism is possible and, contrary to Butler's (1980) view, the development of tourism destinations does not have to end up in stagnation in the long run. Alternate phases of high and low tourist inflows will not be necessary to allow ecosystem regeneration, as long as the household-firm actively engages in environmental preservation activities that support the renewal capacity of natural assets. Since growth and environmental quality move in the same direction, a smooth development process, founded on environmental-based tourism activities, is not simply a utopia, but a concrete possibility.

These results suggest that international tourism competition can play an important role in promoting green growth. What really matters for this result to hold is that such competition is driven by tourists' green preferences, which spur residents' willingness to invest in abatement activities. Tourism, and in particular the nature of tourists' preferences, is the source of the economic incentives leading to the BGP outcome. Since tourists are attracted by greener locations, their demand triggers residents' investment in abatement activities, which, by improving environmental quality, generates long run growth. Since tourists play a determinant role for such an outcome to arise, it is crucial to understand how their preferences affect the BGP. This can be summarized as follows.

Proposition 2: Along the BGP, the economic and environmental growth rates are positive functions of the tourists' green preference parameter $(\phi)$, while they are negative functions of the grey preference $(\alpha)$ and crowding aversion ( $\mu$ ) parameters.

Proof: The result is immediate by differentiating Equations (13) and (14) with respect to $\theta$ (remembering that $\theta=1+\phi-\mu$ increases with $\phi$ and decreases with $\mu$ ) and $\alpha$.

Proposition 2 emphasizes how tourists, with their own preferences, lead a tourism economy to a better or worse outcome in terms of economic and environmental performances. This suggests that (tourists') environmental education can be crucially successful and may be needed to improve the economic and environmental growth rates of several economies worldwide. In particular, education policies aimed at improving the passion of tourists for remote, untouched and environmental-friendly destinations, or lowering their passion for highly urbanized and metropolitan areas or for crowded localities will be beneficial for the whole economic-environmental system of tourism destinations. While the effects of the former two kinds of policy are obvious, the latter 
deserves some explanation. The crowding aversion parameter determining the sympathy of tourists for the presence of other visitors has important implications on the revenues of the tourism sector. Basically, a stronger crowding aversion decreases tourism revenues since tourists are less willing to visit popular destinations and therefore lowers the incentives for residents to invest in abatement activities, which will eventually result in further reductions in tourist flows. Being successful in lowering crowding aversion will allow to get rid of this perverse mechanism generating a vicious circle. ${ }^{8}$

A different interpretation is related to the kind of tourism such preferences would imply. Larger values of $\alpha$ are associated to mass tourism, while larger values of $\phi$ are associated to green-tourism. Indeed, on the one hand, a higher grey preference parameter implies that tourists' interest is mainly linked to human-built facilities and thus not much concerned about environmental problems, while, on the other hand, a higher value of the green preference parameter means that tourists place more value on environmental assets and wish to enjoy more natural amenities. Since the destination may hypothetically choose which type of visitors to attract (through different marketing strategies), these parameters can be read as policy instruments. From this perspective, Proposition 2 states that policy measures fostering the development of green tourism are beneficial to both the economic performance and environmental quality, while other measures promoting mass tourism are harmful for both the economy and the environment. Thus, if tourism needs to be the strategy for long-term development, green-tourism measures have to be encouraged and supported.

\section{Tourism in small island countries}

The model works well in describing the experience of small economies, in particular small island economies, where tourism is the main source of economic activity. Some examples are South Pacific, Indian and Caribbean islands, which, because of their location, their natural endowment and their remoteness, keep struggling to develop an efficient economy, based on agriculture or manufacturing. In these countries, how to manage the trade-off between natural amenities and tourism facilities is an important question and problem. In fact, two competing forces exacerbate the matter: from one side, the desire to attract more tourists who bring and spend their resources in the country, allowing substantial increases in the national income, would push for constructing new facilities to accommodate their needs; from the other side, the necessity to tackle environmental problems, which is a delicate issue in these countries ${ }^{9}$ and can be stressed by tourism activities, would operate in favour of limiting the number of tourists.

Small countries in general, and small island countries in particular, face additional challenges in their development process with respect to larger countries. Because of the difficulty in achieving sufficient economies of scale in a wide variety of basic economic activities, tourism is an important strategy to compensate for their smallness. It provides the volume to address insufficient market demand, it increases competition by encouraging new entrants in the local market and raise the standard of living of the local population (Croes, 2006). Persaud (2011), analysing the development and growth opportunities of 
Caribbean countries, develops a Ricardian argument that can be equally applied to other small economies, such as the Pacific and Indian island countries. $\mathrm{He}$ claims that these countries have the 'luxury of limited choice', in the sense that, being so small, they have no alternative to improve their welfare but to exploit their comparative advantage. In fact, the size of these economies often does not allow them to be competitive with big countries, in either the manufacturing (China and India) or agricultural (Australia and Brazil) sectors. However, they are endowed with significant natural resources, tropical weather and pristine beaches which make them interesting and desired tourism locations. For these economies, tourism is a crucial and often predominant component of the national welfare, thus determining how dealing with increasing tourism demand and tourist needs is a survival matter. Moreover, tourism is often seen by local policymakers as the obvious, or even the only, way to achieve economic development (Crusol et al, 1989). The luxury of limited choice would mainly consist of focusing on the management of the trade-off, often experienced in industrialized economies, between economic development and environmental preservation. ${ }^{10}$

However, tourism is not necessarily a panacea (Commonwealth Secretariat and World Bank, 2000) and its effect on local population's well-being is not obvious and could even be harmful. Indeed, tourism specialization, especially in small countries, could generate several types of perverse effects (dependence on foreign capital, inflation, market labour disturbances, Dutch Disease effect, land competition, the low education trap). The recent experience of the Caribbean islands, where the first signs of deterioration of tourism success are showing, is an example of how compelling the need to manage tourism development is. After decades of success, recent trends show that the Caribbean region receives more customers who spend less and less in the host economy, and in the long-run this could even hamper the development process from continuing smoothly. In fact, an increasing number of tourists spending less money in the tourism destination exacerbates the negative (environmental pressure) and reduces the positive (economic stimulus) aspects of tourism. De Albuquerque and McElroy (1992), as long as 20 years ago, suggested that longrun tourism viability in the region required several islands to adopt a sustainable approach to tourism, following Bermuda's example (where the government limits total arrivals to a maximum sustainable annual level). Maloney and Montes Rojas (2001) argue that the outcome in the Caribbean region is a consequence of mass tourism, which has extensively introduced 'all inclusive' packages and price competition.

Tourism in several Caribbean islands has reached the maturity stage, according to Butler's (1980) life-cycle model (De Albuquerque and McElroy, 1992), and developing an alternative tourism strategy can be extremely costly. However, their experience should serve as a warning for other tourism economies, especially those still in the earlier stages of the life-cycle model, of the possible effects of a lack of long-term perspective in planning tourism development. The Indian and South Pacific islands, where the contribution of tourism to GDP is much lower than that in the Caribbean islands (WTTC, 2012), are still in a phase of emergence and discovery, probably because of the higher travel costs from highly populated rich countries (Europe and North America). They should learn from the Caribbean lesson that mass tourism has largely positive effects 
only in the short term while in the long run it can be associated with excessive (environmental) costs. Wilkinson (1989) suggests that mass tourism cannot be a long-term solution for small islands and that there are alternative actions to develop long-term sustainable tourism, balancing the competing economic and environmental pressures. ${ }^{11}$ The theoretical framework we develop is consistent with Wilkinson's (1989) view and confirms his claim that alternative pathways to tourism, ending up in long-run growth, environmental improvement and welfare gains, do exist.

\section{Extensions}

In this section we consider two straightforward extensions of the model to allow for the governmental provision of public services (as suggested by Cerina, 2007) and a more realistic tourist flow function (Giannoni and Maupertuis, 2007). We show that the qualitative results will not be substantially different in these contexts, and thus our baseline model represents a good benchmark for the analysis of tourism activities on both the economic and environmental sides of tourism destinations.

\section{Government and the provision of public services}

As Cerina (2007) underlines, tourists' preferences may also be positively affected by the provision of public goods, such as transport, information and safety. To allow for this possibility, we now assume that a government or local authority levies proportional taxes on the household-firm agent's income in order to provide such goods and services. If the government wishes to maintain a balanced budget, its public spending, $g_{t}$ will be equal to the tax revenues, $\tau y_{t}$, at any time: $g_{t}=\tau y_{t}$, where $\tau$ is the tax rate. Tourists' preferences and willingness to pay can be rewritten as:

$$
p_{t}=b k_{t}^{\psi_{1}} g_{t}^{\psi_{2}} e_{t}^{\psi_{3}} z_{t}^{-\psi_{4}}
$$

where $\psi_{1}, \psi_{3}, \psi_{4}$ are the tourists' preference parameter with respect to tourism services, environmental quality and number of tourists. It seems reasonable to assume that tourists obtain satisfaction also by the quality and quantity of public services provided by local authorities (Cerina, 2007); thus, the term 0 $<\psi_{2}<1$ measures tourists' sympathy towards public services and we suppose that the willingness to pay for tourism services is increasing and concave in $g_{t}$. By inserting $g_{t}=\tau y_{t}$ into Equation (15), and plugging this into the household-firm's income, we can recast residents' income from tourism activities as:

$$
y_{t}=a k_{t}^{\alpha} e_{t}^{\phi} z_{t}^{1-\mu}
$$

where $a=b^{\frac{1}{1-\psi_{2}}} \frac{\psi_{2}}{1-\psi_{2}}, \alpha=\frac{\psi_{1}}{1-\psi_{2}}, \phi=\frac{\psi_{3}}{1-\psi_{2}}$ and $1-\mu=\frac{1-\psi_{4}}{1-\psi_{2}}$. Note that the expression for income in Equation (16) is exactly equivalent to Equation (2). It is therefore obvious that all the previous results (Propositions 1 and 2) still hold, as long 
as $\frac{\psi_{1}}{1+\epsilon(\sigma-1)}<1-\psi_{2}<\frac{\left(1+\psi_{3}-\psi_{4}\right) r}{\epsilon \rho}$, which ensures that the growth rates of consumption and environmental quality are strictly positive along the BGP. In particular, it is possible to stress the following result.

Proposition 3: Along the BGP, the economic and environmental growth rates are independent of the tax rate $(\tau)$ used to provide public services, and they positively depend on the tourists' public service preference parameter $\left(\psi_{2}\right)$.

Proof: Note that in this framework the economic and environmental growth rates are respectively given by: $\gamma=\frac{\left(1+\psi_{3}-\psi_{4}\right) r-\left(1-\psi_{2}\right) \epsilon \rho}{[1+\epsilon(\sigma-1)]\left(1-\psi_{2}\right)-\psi_{1}}$ and $\gamma_{e}=\frac{1-\psi_{1}-\psi_{2}}{1+\psi_{3}-\psi_{4}} \gamma$. The result is immediate by differentiating these expressions with respect to $A=a v^{1-\mu}=b^{\frac{1}{1-\psi_{2}}} \frac{\psi_{2}}{\tau^{1-\psi_{2}}} v^{1-\mu}$ and $\psi_{2}$. About $\frac{\partial \gamma_{e}}{\partial \psi_{2}}$, a sufficient condition for this derivative to be monotonic (and positive) is that $\psi_{1}+\psi_{2}<1$.

The reason why the economic and environmental growth rates are not affected by the tax rate used to finance public services is related to the fact that the government provides such services by subtracting resources to the household-firm agent. This implies that the same resources that in the absence of government intervention were used to provide tourism services would now be used to provide public services also. Since these two types of tourism services are substitutable in tourists' preferences and they do not affect the environment (the engine of growth), the global effect on growth rates is null. The result that growth rates increase with the public service preference parameter is not surprising and is consistent with the results in Proposition 2.

\section{Different tourists flow function}

Our baseline model is based on the simplifying assumption that tourist flows depend only on the stock of natural resources; see Equation (6). This does not consider the eventual substitutability ${ }^{12}$ between natural amenities (environmental stock) and human-built facilities (tourism capital stock). Similarly to Giannoni and Maupertuis (2007), where the number of tourists monotonically rises both with the quality of the environment and quantity of tourism services, we now assume that tourist flows are determined by both the stock of natural resources and tourism facilities through the following function:

$$
z_{t}=v e_{t}^{\delta} k_{t}^{\lambda},
$$

where $\delta, \lambda \in[0,1]$ imply that (reasonably) tourism is increasing and concave in $e_{t}$ and $k_{t}$. Under Equation (17), our model can be recast as follows:

$$
\begin{aligned}
\max _{c_{t}, u_{t}} \quad W & =\int_{0}^{\infty} \frac{c_{t}^{1-\sigma}-1}{1-\sigma} e^{-\rho t} d t, \\
\text { s.t. } \quad \dot{k}_{t} & =\left(1-u_{t}\right)^{\epsilon} A k_{t}^{\beta} e_{t}^{\theta}-c_{t}, \\
\dot{e}_{t} & =r e_{t}-\eta\left(1-u_{t}\right) k_{t}^{\lambda} e_{t}^{\delta} .
\end{aligned}
$$


where $A=a v^{1-\mu}, \beta=\alpha+\lambda(1-\mu), \theta=\phi+\delta(1-\mu)$ and $\eta=d v$. Provided that the conditions to ensure the sufficiency of such an optimization problem are met, ${ }^{13}$ it is possible to show that a result pretty similar to that derived in Proposition 1 holds.

Proposition 4: Assume $\mathrm{r}>\frac{\epsilon}{\theta+\epsilon(1-\delta)} \rho$. Then, the following results hold:

(i) Along the BGP, the economic and environmental growth rates are strictly positive and respectively given by:

$$
\begin{aligned}
& \gamma=\frac{[\theta+\epsilon(1-\delta)] \mathrm{r}-\epsilon \rho}{1-\beta+\epsilon(\sigma-1+\lambda)^{\prime}} \\
& \gamma_{\mathrm{e}}=\frac{1-\beta+\epsilon \lambda}{\theta+\epsilon(1-\delta)} \gamma .
\end{aligned}
$$

(ii) The BGP is the only (non-trivial) viable equilibrium.

Proof: See the Appendix.

The comments regarding Propositions 1 and 2 still apply in this framework; note that in the case $\delta=1$ and $\lambda=0$ (such that $\beta=\alpha$ ), the model is completely equivalent to our baseline specification and thus the results are perfectly equivalent. However, in this case since tourist flows depend on both the stock of natural and tourism assets, we are not able to determine explicitly what the share of unabated emissions in steady state is, and thus we are unable to provide an upper bound for $r$. Proposition 4 shows that even if tourist flows allow for a substitutability between environmental and tourism capital stocks, a sustainable BGP equilibrium can be found, and along such a path a smooth process of economic development and environmental improvement occurs. As long as the household-firm agent engages in environmental protection activities, a sustainable outcome for environmental-based tourism economies is possible.

\section{Conclusion}

Tourism, as any human activity, strongly affects and is affected by the environment. For countries highly dependent on tourism, understanding how to regulate its development is of great significance. We construct a theoretical framework in which international tourists choose their holiday destination according to their preferences for greenness, greyness and crowding while resident household-firm agents determine their effort in environmental protection activities. Since tourism provides residents with incentives to engage in environmental protection, the economy will reach a sustainable balanced growth path along which income, welfare and environmental quality rise. This suggests that the long-run sustainability of tourism is not a utopian ideal, but it requires a careful management of environmental assets. Thus, a carefully planned tourism sector can represent an important tool for promoting green growth in several developing countries, where tourism's contribution to GDP may become larger and larger in the future. 
In the debate on how to boost economic growth in developing countries, especially at a small country level, policymakers often look at tourism development as the unique solution. In particular, in order to raise revenues from tourism activities, they encourage mass tourism. In their view, this would increase income of the local population and thus its well-being. However, this view does not to take into account the implications on natural resources, which are an important driver of worldwide tourists' destination choice and therefore can determine the eventual success in the long-run of any tourism activity. As Wilkinson (1989) suggests, mass tourism cannot be a solution for small developing island countries. In this paper we provide a theoretical support to his argument by showing that long-run tourism-based growth will be possible if the preservation of natural resources is a central focus for local agents and if worldwide tourists have strong preferences for greener destinations. While the latter condition is to a large extent out of the control of local policymakers, the former deserves special attention. Postponing environmental protection to the later stages of economic development can be an hazardous choice: if tourism specialization needs to be the pathway to development, green tourism needs to be promoted to ensure that the development process will be smooth and sustainable.

Our results are obtained from a framework in which tourist flows are endogenous as a result of the residents' choice of how much to consume and devote to environmental protection. Several studies relying on the concept of carrying capacity point out that the number of tourists should be carefully controlled (De Albuquerque and McElroy, 1992); thus a direct extension of the model would involve determining the optimal number of tourists and analysing its dynamic patterns. Other recent works analyse how uncertainty affects economic decisions in multi-sector economic growth frameworks similar to ours (Marsiglio and La Torre, 2012a, 2012b); thus it would also be interesting to understand to what extent the degree of uncertainty about tourist demand impacts on tourism revenues, tourism and natural assets. Finally, another line of future research, probably the most challenging, would consist of combining our results with a dynamic model of trade (Hazari and Sgro, 1995) to analyse whether and how terms of trade, growth and environment affect one another. This is left for future research.

\section{Endnotes}

1. Budowsky (1976) critically discusses whether tourist flows lead to degradation or enhancement of the environment, and claims that three types of interrelation between tourism and environment can exist: conflict, coexistence or symbiosis.

2. Note that in the paper the terms 'environmental assets', 'environmental quality' and 'natural resources' are used synonymously. Similarly, the terms 'tourism facilities' and 'tourism capital' (or simply 'capital') are interchangeable.

3. This is obviously a strong simplification of reality. However, also introducing a demand side in such a dynamic context would dramatically complicate the model, and it would no longer be possible to obtain analytical solutions.

4. Cerina (2007, p 556) emphasizes that many factors affect tourism preferences; in particular: '... a foreign visitor obtains satisfaction from a number of different sources, such as: (a) the quality and quantity of services supplied by private tourist operators (accommodation, restaurants, leisure facilities); (b) the quality and quantity of public goods provided by local authorities (public transport, information, safety); (c) the quality and quantity of environmental (amenities, countryside, beaches, mountains, parks, climate), cultural (traditional 
festivals and events, typical food, historical buildings, museums) and social (people, general atmosphere, curious attractions) resources; and (d) the degree of availability and enjoyment derived from public goods and cultural and environmental amenities, which is highly correlated to and negatively influenced by the aggregate number of visitors.'

Note that, apart from public goods, our model includes all such factors. In a later section of the paper, we shall also introduce a government with the goal of providing public goods and services, showing that our results will not be qualitatively different.

5. However, a restriction on the sign of $\mu$ will be imposed later on to ensure sufficiency of the optimal control problem. In particular, we shall need the degree of crowding aversion to be positive.

6. The assumption will be removed later, when we consider that tourist flows are also related to the stock of tourism facilities (Giannoni and Maupertuis, 2007). Since the qualitative results of the baseline model still hold even in more detailed frameworks (see the fifth section), we believe it is appropriate to present the model first in its simplest form.

7. Note that the structure of the economy allows a model of tourism to be obtained that is directly comparable to traditional models of economic growth. In particular, the model can be directly read as a Uzawa (1965)-Lucas (1988) type growth model in which tourism facilities and environmental resources represent physical and human capital, respectively. Different from the standard Uzawa-Lucas model, in our framework income (output) rather than input (share of human capital) is used to reallocate resources between sectors. The allocation of a certain amount of income to environmental preservation activities ensures that (under particular conditions) the growth rate of natural resources is strictly positive, and thus the environment turns out to be the engine of growth.

8. The result that education can be an important vehicle to make people's, in particular tourists', preferences and behaviour greener is consistent with several studies in educational psychology (see, among others, Orams and Hill, 1998). These studies lend support to our conclusion that environmental education deserves greater emphasis in tourism (and more broadly speaking, in environmental) management issues.

9. Climate change is a great challenge for small islands around the world. The Intergovernmental Panel on Climate Change (2007) identifies Tuvalu, Kiribati, the Marshall Islands in the Pacific and the Maldives in the Indian Ocean as key sites vulnerable to the sea-level rise resulting from climate change.

10. Persaud's (2011, p 9) words clearly emphasize this reasoning:

'Where countries are physically small and tourism is a large component of the economy, it is critical to invest in preserving and enriching the natural, constructed and social environment. There is no space to waste in a small state. Islands that are dependent on tourism disregard, at their peril, issues such as coastal management, water runoffs, waste management and social issues that keep tourists away - drugs, crime, corruption and general lawlessness.'

11. Wilkinson (1989) stresses that, while tourism, because of its nature, always results in some environmental change, the route to environmental damage is not predetermined and that alternative, eventually less-damaging, options exist. In this context he believes that tourism firms need to treat environmental protection as an 'internality'; that is, as a cost of doing business.

12. According to Equation (6), tourist flows increase over time only if environmental quality increases too; a more realistic situation is where, even if environmental quality does not change (or even falls), tourism inflows may rise because of increases in the stock of tourism facilities.

13. By assuming that $\beta<1$ and $\beta+\theta<1$ (the same conditions introduced in the baseline model), some additional conditions are needed to ensure sufficiency. These are met if $\epsilon$ is large enough, and at the same time $\beta>\lambda$ and $\theta>\delta$.

\section{References}

Bartz, S., and Kelly, D.L. (2008), 'Economic growth and the environment: theory and facts', Resource and Energy Economics, Vol 30, No 2, pP 115-149.

Brau, R., Lanza, A., and Pigliaru, F. (2007), 'How fast are small tourism countries growing? Evidence for the data 1980-2003', Tourism Economics, Vol 13, No 4, pp 603-614.

Brock, W.A., and Taylor, M.S. (2010), 'The green Solow model', Journal of Economic Growth, Vol 15, No 2, pp 127-153.

Budowsky, G. (1976), 'Tourism and environmental conservation: conflict, coexistence or symbiosis?', Environmental Conservation, Vol 3, No 1, pp 27-31. 
Butler, R.W. (1980), 'The concept of a tourist area cycle of evolution: implications for management of resources', Canadian Geographer, Vol 24, No 1, pp 5-12.

Candela, G., and Cellini, R. (2006), 'Investment in tourism market: a dynamic model of differentiated oligopoly', Environmental and Resource Economics, Vol 35, No 1, pp 41-58.

Casagrandi, R., and Rinaldi, S. (2002), 'A theoretical approach to tourism sustainability', Conservation Ecology, Vol 6, No 1, article 13.

Cerina, F. (2007), 'Tourism specialization and environmental sustainability in a dynamic economy', Tourism Economics, Vol 13, No 4, pp 553-582.

Commonwealth Secretariat and World Bank (2000), 'Small states: meeting challenges in the global economy', Report by the Commonwealth Secretariat/World Bank joint task force on small states, (http://www.thecommonwealth.org/Shared ASP Files/UploadedFiles/03D192EA-CCF2-4FA2_ 96B3-F7DA64AD245B taskforcereport.pdf).

Croes, R.R. (2006), 'A paradigm shift to a new strategy for small island economies: embracing demand side economics for value enhancement and long term economic stability', Tourism Management, Vol 27, No 3, pp 453-465.

Crusol, J., Hein, P., and Vellas, F. (1989) L'enjeu Des Petites Economies Insulaires, Economica, Paris.

Davies, T., and Cahill, S. (2000), 'Environmental implications of the tourism industry', Discussion Paper 00-14, Resources for the Future, Washington, DC.

De Albuquerque, K., and McElroy, J.L. (1992), 'Caribbean small-island tourism styles and sustainable strategies', Environmental Management, Vol 16, No 5, pp 619-632.

Dearden, P. (1991), 'Tourism and sustainable development in Northern Thailand', Geographical Review, Vol 81, No 4, pp 400-413.

Giannoni, S., and Maupertuis, M. (2007), 'Environmental quality and optimal investment in tourism infrastructures: a small island perspective', Tourism Economics, Vol 13, No 4, pp 499-513.

Hazari, B.R., and Sgro, P. (1995), 'Tourism and growth in a dynamic model of trade', Journal of International Trade \& Economic Development, Vol 4, No 2, pp 243-252.

Lanza, A., and Pigliaru, F. (2000), 'Why are tourism countries small and fast-growing?', in Fossati A., and Panella, G., eds, Tourism And Sustainable Economic Development, Kluwer Academic Publisher, Dordrecht, pp 57-69.

Lanza, A., Temple, P., and Urga, G. (2003), 'The implications of tourism specialisation in the long run: an econometric analysis for 13 OECD economies', Tourism Management, Vol 24, No 3, pP 315-321.

Lozano, J., Gomez, C.M., and Rey-Maquieira, J. (2008), 'The TALC hypothesis and economic growth theory', Tourism Economics, Vol 14, No 4, pp 727-749.

Lucas, R.E. (1988), 'On the mechanics of economic development', Journal of Monetary Economics, Vol 22, No 1, pp 3-42.

Maloney, W.F., and Montes Rojas, G.B. (2001), Demand for Tourism, The World Bank, Washington, DC.

Marsiglio, S. (2011), 'On the relationship between population change and sustainable development', Research in Economics, Vol 65, No 4, pp 353-364.

Marsiglio, S., and La Torre, D. (2012a) 'Population dynamics and utilitarian criteria in the LucasUzawa model', Economic Modelling, Vol 29, No 4, pp 1197-1204.

Marsiglio, S., and La Torre, D. (2012b), 'A note on demographic shocks in a multi-sector growth model', Economics Bulletin, Vol 32, No 3, pp 2293-2299.

Orams, M.B., and Hill, G.J.E. (1998), 'Controlling the ecotourist in a wild dolphin feeding program: is education the answer?', Journal of Environmental Education, Vol 29, No 3, pp 33-38.

Persaud, A.D. (2011), 'Fostering growth and development in small States through disruptive change: a case study of the Caribbean', CIGI Papers, Caribbean Paper 11, Center for International Governance Innovation, Waterloo, Ontario.

Pigram, J. (1990), 'Sustainable tourism: policy considerations', Journal of Tourism Studies, Vol 1, No 2, pp 2-9.

Ramsey, F. (1928) 'A mathematical theory of saving', Economic Journal, Vol 38, No 152, pp 543-559.

Rosen, S. (1974), 'Hedonic prices and implicit markets: product differentiation in pure competition', Journal of Political Economy, Vol 82, No 1, pp 34-55.

Schubert, S.F., Brida, J.G., and Risso, W.A. (2011), 'The impacts of international tourism demand on economic growth of small economies dependent on tourism', Tourism Management, Vol 32, No 2, pp 377-385.

Solow, R. (1974), 'Intergenerational equity and exhaustible resources', Review of Economic Studies, Vol 41, No 5, pp 29-45. 
Stokey, N. (1998), 'Are there limits to growth?', International Economic Review, Vol 39, No 1, pp 131.

Tisdell, C.A. (2001), Tourism Economics, The Environment And Development, Edward Elgar, Cheltenham.

Uzawa, H. (1965), 'Optimum technical change in an aggregate model of economic growth', International Economic Review, Vol 6, No 1, pp 18-31.

Wilkinson, P.F. (1989), 'Strategies for tourism in island microstates', Annals of Tourism Research, Vol 16, No 2, pp 153-177.

WCED (World Commission on Environment and Development) (1987), Our Common Future, Oxford University Press, Oxford.

WTO (World Tourism Organization) (1998), Guide For Local Authorities On Developing Sustainable Tourism, WTO, Madrid.

WTTC (World Travel and Tourism Council) (2012), 'The comparative economic impart of travel and tourism 2012' (http://www.wttc.org/focus/research-for-action/benchmark-reports/the-comparative-economic-impact-of-travel-tourism/, accessed 19 February 2015).

Xepapadeas, A. (2005), 'Economic growth and the environment', in Maler, K.G., and Vincent, J.R., eds, Handbook of Environmental Economics: Volume 3, North Holland, Amsterdam, pp 1219-1271.

\section{Appendix: equilibrium and stability analysis}

\section{Baseline model}

By introducing $\chi_{t}=\frac{c_{t}}{k_{t}}$ and $\varphi_{t}=k_{t}^{\alpha-1} e_{t}^{\theta}\left(1-u_{t}\right)^{\epsilon}$, we obtain the following reduced quasi-linear system of differential equations:

$$
\begin{aligned}
& \frac{\dot{\chi}_{t}}{\chi_{t}}=\frac{\alpha-\sigma}{\sigma} A \varphi_{t}+\chi_{t}-\frac{\rho}{\sigma}, \\
& \frac{\dot{\varphi}_{t}}{\varphi_{t}}=(\alpha-1) A \varphi_{t}+\frac{\epsilon-1+\alpha}{\epsilon-1} \chi_{t}-\frac{\theta}{\epsilon-1} r, \\
& \frac{-\dot{u}_{t}}{1-u_{t}}=\frac{1}{\epsilon-1}\left[\alpha \chi_{t}+\frac{\theta(\epsilon-1) \eta}{\epsilon}\left(1-u_{t}\right)-\theta r\right] .
\end{aligned}
$$

Its steady state, found by setting Equations (23), (24) and (25) equal to zero, is given by $(\bar{\chi}, \bar{\varphi}, 1-\bar{u})$, where:

$$
\begin{aligned}
& \bar{\chi}=\frac{\theta(\sigma-\alpha) r-(\epsilon-1)(1-\alpha) \rho}{\alpha[1-\alpha+\epsilon(\sigma-1)]}, \\
& \bar{\varphi}=\frac{\theta \sigma r-(\epsilon-1+\alpha) \rho}{A \alpha[1-\alpha+\epsilon(\sigma-1)]} \\
& 1-\bar{u}=\frac{\epsilon[(\sigma-1) \theta r+(1-\alpha) \rho]}{\theta \eta[1-\alpha+\epsilon(\sigma-1)]} .
\end{aligned}
$$

For $\bar{\varphi}$ to be positive we need $r>\frac{\epsilon-1+\alpha}{\theta \sigma} \rho$, while for $\bar{\chi}$ to be positive we need $r>\frac{(\epsilon-1)(1-\alpha)}{\theta(\sigma-\alpha)} \rho$. Since $\epsilon>1$, as long as $r>\frac{\epsilon-1+\alpha}{\theta \sigma} \rho$ holds the previous inequality is met. Note that $1-\bar{u}$ is positive with no further parameter restrictions, and 
in order to be less than unity we need: $r<\frac{\theta \eta[1-\alpha+\epsilon(\sigma-1)]-\epsilon(1-\alpha) \rho}{\theta \epsilon(\sigma-1)}$. We can now find the growth rate of consumption and environment at steady state, given by Equations (13) and (14). For both of them to be positive we need $r>\frac{\epsilon}{\theta} \rho$, which also implies $r>\frac{\epsilon-1+\alpha}{\theta \sigma} \rho$. For this set of parameter restrictions to make sense, we need $r<\frac{\theta \eta[1-\alpha+\epsilon(\sigma-1)]-\epsilon(1-\alpha) \rho}{\theta \epsilon(\sigma-1)}$ to be larger than $\frac{\epsilon}{\theta} \rho$, which requires $\eta>\frac{\epsilon}{\theta} \rho$. As long as $r<\eta$, this last inequality is implied by $r>\frac{\epsilon}{\theta} \rho$. Therefore the range of values for $r$ is given by the following expression: $\frac{\epsilon}{\theta} \rho<r<\frac{\theta \eta[1-\alpha+\epsilon(\sigma-1)]-\epsilon(1-\alpha) \rho}{\theta \epsilon(\sigma-1)}$.

We can study the stability property of the equilibrium $(\bar{\chi}, \bar{\varphi}, 1-\bar{u})$ by linearization. The Jacobian matrix evaluated at steady state reads as:

$$
J(\bar{\chi}, \bar{\varphi}, 1-\bar{u})=\left[\begin{array}{ccc}
\bar{\chi} & -\frac{\sigma-\alpha}{\sigma} A \bar{\chi} & 0 \\
\frac{\epsilon-1+\alpha}{\epsilon-1} \bar{\varphi} & -(1-\alpha) A \bar{\varphi} & 0 \\
\frac{\alpha}{\epsilon-1}(1-\bar{u}) & 0 & \frac{\theta \eta}{\epsilon}(1-\bar{u})
\end{array}\right] .
$$

The stability properties of the system represented by Equations (23), (24), (25) depends on the number of positive and negative eigenvalues of $J(\bar{\chi}, \bar{\varphi}, 1-\bar{u})$. We can explicitly find the three eigenvalues, which are given by:

$$
\begin{aligned}
& \lambda_{1}=\frac{\theta \eta}{\epsilon}(1-\bar{u}), \\
& \lambda_{2,3}=\frac{1}{2}\left(\Gamma \pm \sqrt{\Gamma^{2}-4 \Theta}\right),
\end{aligned}
$$

where $\Gamma=\frac{\theta \eta}{\epsilon}(1-\bar{u})>0$ and $\Theta=\frac{\alpha \epsilon(\sigma-1)+\alpha(1-\alpha)}{\sigma(\epsilon-1)} A \overline{\varphi \chi}>0$. It is straightforward to note that $\lambda_{1}$ is positive, and $\lambda_{2,3}$ have both positive real parts whatever the sign of the difference $\Gamma^{2}-4 \Theta$ is, since $\Theta>0$. Since all the eigenvalues have positive real parts, the equilibrium is locally unstable and therefore the only viable (nontrivial) equilibrium for our model economy is to lie on its BGP equilibrium at any point in time.

\section{Extended model}

The Euler equations for consumption and share of abated emissions for the problem of Equations (18), (19) and (20) are given by:

$$
\begin{aligned}
& \frac{\dot{c}_{t}}{c_{t}}=\frac{1}{\sigma}\left[(\beta-\lambda \epsilon)\left(1-u_{t}\right)^{\epsilon} A k_{t}^{\beta-1} e_{t}^{\theta}-\rho\right] \\
& -\frac{\dot{u}_{t}}{1-u_{t}}=\frac{1}{\epsilon-1}\left[\frac{\theta}{\epsilon}(\epsilon-1) \eta\left(1-u_{t}\right) k_{t}^{\phi} e_{t}^{\delta-1}+(\delta-\theta-1) r-(\lambda-\beta) \frac{c_{t}}{k_{t}}\right. \\
& \left.-\phi(\epsilon-1)\left(1-u_{t}\right)^{\epsilon} A k_{t}^{\beta-1} e_{t}^{\theta}\right] .
\end{aligned}
$$


By introducing $\chi_{t}=\frac{c_{t}}{k_{t}}, \varphi_{t}=k_{t}^{\beta-1} e_{t}^{\theta}\left(1-u_{t}\right)^{\epsilon}$ and $\psi_{t}=k_{t}^{\lambda} e_{t}^{\delta-1}\left(1-u_{t}\right)$, we can analyse the following system of differential equations:

$$
\begin{aligned}
& \frac{\dot{\chi}_{t}}{\chi_{t}}=\frac{\beta-\lambda \epsilon-\sigma}{\sigma} A \varphi_{t}+\chi_{t}-\frac{\rho}{\sigma}, \\
& \frac{\dot{\varphi}_{t}}{\varphi_{t}}=(\beta-\lambda \epsilon-1) A \varphi_{t}+\frac{\epsilon(1-\phi)+\beta-1}{\epsilon-1} \chi_{t}-\frac{\theta+\epsilon(1-\delta)}{\epsilon-1} r, \\
& \frac{\dot{\psi}_{t}}{\psi_{t}}=\frac{\theta+\epsilon(1-\delta)}{\epsilon} \eta \psi_{t}-\frac{\theta+\epsilon(1-\delta)}{\epsilon-1} r+\frac{\beta-\lambda \epsilon}{\epsilon-1} \chi_{t} .
\end{aligned}
$$

Its equilibrium is given by $(\bar{\chi}, \bar{\varphi}, \bar{\psi})$, where:

$$
\begin{aligned}
& \bar{\chi}=\frac{(\sigma-\beta+\lambda \epsilon)[\theta+\epsilon(1-\delta)] r-(\epsilon-1)(1-\beta+\lambda \epsilon) \rho}{(\beta-\lambda \epsilon)[1-\beta+\epsilon(\sigma-1+\lambda)]}, \\
& \bar{\varphi}=\frac{\sigma[\theta+\epsilon(1-\delta)] r-[\epsilon(1-\phi)+\beta-1] \rho}{A(\beta-\lambda \epsilon)[1-\beta+\epsilon(\sigma-1+\lambda)]} \\
& \bar{\psi}=\frac{\epsilon\{(\sigma-1)[\theta+\epsilon(1-\delta)] r+(1-\beta+\lambda \epsilon) \rho\}}{\eta[\theta+\epsilon(1-\delta)][1-\beta+\epsilon(\sigma-1+\lambda)]}
\end{aligned}
$$

The condition $r>\frac{\epsilon}{\theta+\epsilon(1-\delta)} \rho$ ensures that $(\bar{\chi}, \bar{\varphi}, \bar{\psi})>0$. The growth rate of consumption and environment are respectively given by: $\gamma=\frac{1}{\sigma}[(\beta-\lambda \epsilon) A \bar{\varphi}-\rho]$ and $\gamma_{e}=r-\eta \bar{\psi}$; plugging Equations (33) and (34) in these expressions gives the BGP growth rates in Equations (21) and (22).

The Jacobian matrix of the previous system of differential equations evaluated at steady state is:

$$
J(\bar{\chi}, \bar{\varphi}, \bar{\psi})=\left[\begin{array}{ccc}
\bar{\chi} & \frac{\beta-\lambda \epsilon-\sigma}{\sigma} A \bar{\chi} & 0 \\
\frac{\epsilon(1-\phi)+\beta-1}{\epsilon-1} \bar{\varphi} & (\beta-\lambda \epsilon-1) A \bar{\varphi} & 0 \\
\frac{\beta-\lambda \epsilon}{\epsilon-1} \bar{\psi} & 0 & \frac{\theta+\epsilon(1-\delta)}{\epsilon} \eta \bar{\psi}
\end{array}\right]
$$

Also in this case we can explicitly find its eigenvalues, which result to be:

$$
\begin{aligned}
& \lambda_{1}=\frac{\theta+\epsilon(1-\delta)}{\epsilon} \eta \bar{\psi}, \\
& \lambda_{2,3}=\frac{1}{2}\left(\Gamma \pm \sqrt{\Gamma^{2}-4 \Theta}\right),
\end{aligned}
$$

where $\Gamma=\frac{\theta+\epsilon(1-\delta)}{\epsilon} \eta \bar{\psi}>0$ and $\Theta=\frac{(\beta-\lambda \epsilon)[1-\beta+\epsilon(\sigma-1+\lambda)]}{\sigma(\epsilon-1)} A \overline{\varphi \chi}>0$. For the same argument 
discussed in the baseline model, $\lambda_{1}$ turns out to be positive, and $\lambda_{2,3}$ to have both positive real parts. Since all the eigenvalues have positive real parts, the equilibrium is locally unstable and therefore the only viable (non-trivial) equilibrium for our model economy is to lie on its BGP equilibrium at any point in time. 